\title{
Incomplete endoscopic resection of colorectal polyps: a prospective quality assurance study
}

\author{
GRAPHICAL ABSTRACT
}

Question: What is the risk of incomplete polypectomy, and what factors can explain the incomplete resection rate?

Answer: Polyps located in the proximal colon and polyps with sessile serrated histology were at much higher risk of being incompletely resected compared with polyps located in the distal colon and polyps with adenomatous histology. There was no difference in polypectomy performance between board-certified gastroenterologists and trainees.

\section{Adenomas SSA/Ps Hyperplastic polyps}

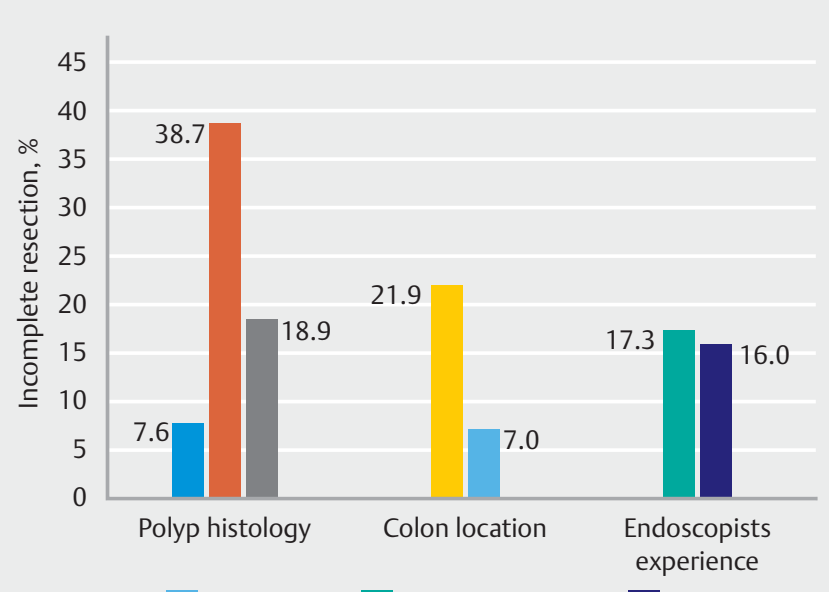

Proximal colon Distal colon — Board-certified GE $\square$ GE in training

Authors

Ina B. Pedersen ${ }^{1,2}$, Michael Bretthauer ${ }^{2,3}$, Mette Kalager ${ }^{2,3}$, Magnus Løberg ${ }^{2,3}$, Geir Hoff ${ }^{4,5}$, Senaria Matapour ${ }^{6}$, Silje Hugin $^{6}$, Svein O. Frigstad ${ }^{6}$, Birgitte Seip ${ }^{4,7}$, Britta A. Kleist ${ }^{8}$, Leif Løvdal ${ }^{8}$, Edoardo Botteri ${ }^{4}$, Øyvind Holme ${ }^{1,2,3,4}$

\section{Institutions}

1 Department of Medicine, Sorlandet Hospital Kristiansand, Kristiansand, Norway

2 Clinical Effectiveness Research Group, University of Oslo, Oslo, Norway

3 Clinical Effectiveness Research Group, Department of Transplantation Medicine, Oslo University Hospital, Oslo, Norway

4 Section for Colorectal Cancer Screening, Cancer Registry of Norway, Oslo, Norway

5 Department of Medicine, Telemark Hospital Skien, Skien, Norway

6 Department of Medicine, Vestre Viken Hospital Trust, Gjettum, Norway

7 Department of Medicine, Vestfold Hospital Trust, Tønsberg, Norway

8 Department of Pathology, Sorlandet Hospital Kristiansand, Norway

submitted 9.12.2019

accepted after revision 15.7.2020

published online 22.9.2020
Bibliography

Endoscopy 2021; 53: 383-391

DOI 10.1055/a-1243-0379

ISSN 0013-726X

(c) 2020. Thieme. All rights reserved.

Georg Thieme Verlag KG, Rüdigerstraße 14,

70469 Stuttgart, Germany

$\circledast$ Supplementary material

Supplementary material is available under

https://doi.org/10.1055/a-1243-0379

\# Scan this QR-Code for the author commentary.

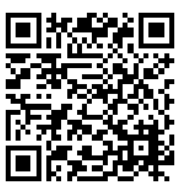

Corresponding author

Ina B. Pedersen, MD, Sørlandet Hospital, Post box 416,

$\mathrm{N}-4604$ Kristiansand, Norway

Fax: +47-37083551

inaborgenheimpedersen@gmail.com 


\section{ABSTRACT}

Background Endoscopic screening with polypectomy has been shown to reduce colorectal cancer incidence in randomized trials. Incomplete polyp removal and subsequent development of post-colonoscopy cancers may attenuate the effect of screening. This study aimed to quantify the extent of incomplete polyp removal.

Methods We included patients aged $50-75$ years with nonpedunculated polyps $\geq 5 \mathrm{~mm}$ removed during colonoscopy at four hospitals in Norway. To evaluate completeness of polyp removal, biopsies from the resection margins were obtained after polypectomy. Logistic regression models were fitted to identify factors explaining incomplete resection.
Results 246 patients with 339 polyps underwent polypectomy between January 2015 and June 2017. A total of 12 polyps were excluded due to biopsy electrocautery damage, and 327 polyps in 246 patients (mean age 67 years [range 42-83]; $52 \%$ male) were included in the analysis. Overall, 54 polyps (15.9\%) in 54 patients were incompletely resected. Histological diagnosis of the polyp (sessile serrated lesions vs. adenoma, odds ratio [OR] 10.9, 95\% confidence interval $[\mathrm{Cl}] 3.9-30.1$ ) and polyp location (proximal vs. distal colon, OR $2.8,95 \% \mathrm{Cl} 1.0-7.7$ ) were independent risk factors for incomplete removal of polyps $5-19 \mathrm{~mm}$. Board-certified endoscopists were not associated with lower rates of incomplete resection compared with trainees ( $14.0 \%$ vs. $14.2 \%)$, OR 1.0 ( $95 \% \mathrm{Cl} 0.5-2.1)$.

Conclusion Incomplete polyp resection was frequent after polypectomy in routine clinical practice. Serrated histology and proximal location were independent risk factors for incomplete resection. The performance of board-certified gastroenterologists was not superior to that of trainees.

\section{Introduction}

Endoscopic screening for colorectal cancer (CRC) has been shown to reduce CRC incidence by $23 \%-33 \%$ in randomized trials [1-4]. This is achieved by resection (polypectomy) of adenomas and serrated polyps, which are CRC precursors. However, there is growing concern that a substantial number of patients have residual polyp tissue after what is believed to be complete resection $[5,6]$. Recent evidence shows that a significant number of polyps are incompletely removed. As many as $31 \%$ of large and sessile or flat polyps recur [6]. Incomplete polypectomy may have significant clinical implications, potentially accounting for as many as $19 \%-27 \%$ of cancers occurring before the next scheduled colonoscopy (interval cancer) $[5,7,8]$.

Polypectomy technique varies between endoscopists [911]. Different techniques may lead to important differences in the ability to remove polyps completely. The proportion of incompletely removed polyps has been shown to vary more than threefold between endoscopists [12]. Systematic training and better techniques may improve polypectomy; for example, injection of submucosal fluid (endoscopic mucosal resection [EMR]) may facilitate complete removal even in polyps of less than $1 \mathrm{~cm}$ in diameter [13].

In order to improve the quality of care for patients with colorectal polyps, it is important to know the rate of incomplete resection. Traditionally, experienced endoscopists teach less experienced colleagues how to perform polypectomies. However, if the endoscopy technique is suboptimal, experience alone is not necessarily associated with high quality. Whether or not experience by itself is associated with incomplete resection of colorectal polyps is unknown.

The aim of the present study was to estimate the rate of incomplete polyp removal and to determine risk factors associated with incomplete polyp resection at multiple centers and between endoscopists in Norway.

\section{Methods}

\section{Study design and patients}

This prospective study was conducted at four hospitals in Norway between January 2015 and June 2017. Patients aged between 50 and 75 years who were scheduled for outpatient colonoscopy were eligible for the study and were included if they had at least one nonpedunculated polyp $\geq 5 \mathrm{~mm}$. Pedunculated polyps found in the same patient were not included in the analyses. We excluded patients who had previously undergone biopsy or attempted polypectomy of the polyp considered for inclusion, who used clopidogrel or other non-acetylsalicylic acid platelet inhibitors within the 5 days before the scheduled colonoscopy, who had an international normalized ratio $>1.8$, or who had severe comorbidity. A total of 21 endoscopists participated in the study. Of these, 9 were board-certified gastroenterologists and 12 were trainee gastroenterologists. Their mean experience as colonoscopists were 14.3 years and 1.8 years, respectively. In Norway, the minimum requirement to become a board-certified gastroenterologist is at least 50 polypectomies. Many endoscopists reach this number long before their training period has finished, and most polypectomies after the first 50 are therefore performed without direct supervision.

\section{Procedures}

Prior to the colonoscopy, all patients ingested a split-dose bowel preparation of sodium picosulphate/magnesium citrate and 2-4 $\mathrm{L}$ of additional fluid, depending on local procedures. Colonoscopies were performed with $130-\mathrm{cm}$ variable-stiffness colonoscopes (Olympus Corp., Hamburg, Germany). The choice of polypectomy technique was at the discretion of the endoscopist ( $\triangleright$ Fig. 1 ). Endoscopists estimated polyp size by reference to a biopsy forceps or snare. After polypectomy, the 

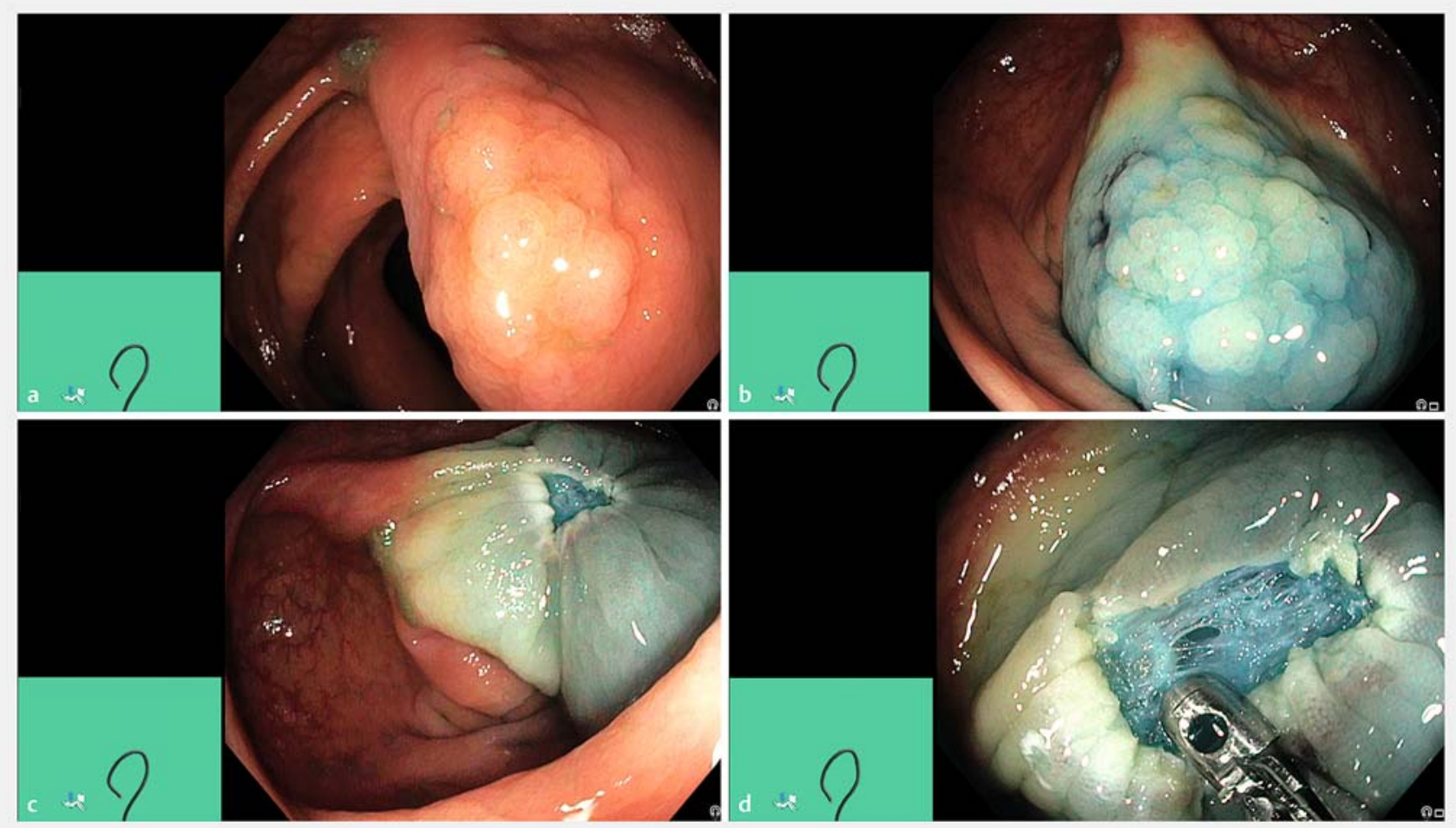

Fig. 1 Example images of a polypectomy procedure. a Polyp. b Polyp after submucosal injection. c Resection margins after polypectomy. d Close-up of resection margins with biopsy forceps. Source: Sørlandet Sykehus

endoscopists rinsed the polypectomy site with water to improve visualization, closely examined the area with white-light and narrow-band imaging, and removed visible polyp remnants. Subsequently, endoscopists obtained biopsies (two from polyps $<10 \mathrm{~mm}$ and four [quadrant] from polyps $\geq 10$ $\mathrm{mm}$ ) from the resection margins, using a 2.2 -mm biopsy forceps. All polyps and corresponding margin biopsies were sent in separate containers with formaldehyde to the pathologist for histopathological assessment. The polyp and corresponding biopsies were examined by the same pathologist. This was done to maximize the likelihood that possible residual polyp tissue was detected, as the pathologist was aware of the type of tissue to look for in the biopsies after examining the polyp.

The endoscopist recorded the following data on a dedicated paper form immediately after the procedure: age and sex of the patient, indication for colonoscopy (screening, symptoms), polyp size (diameter in $\mathrm{mm}$ ), and polyp location (proximal for polyps proximal to and including the splenic flexure; distal for polyps distal to the splenic flexure), polypectomy method (with or without electrocautery, with or without submucosal injection [EMR] with contrast agent [e.g. indigo carmine], en bloc or piecemeal resection), complications, and endoscopist's identification. We defined different levels of polypectomy difficulty according to the time needed for complete polyp removal: easy ( $<2$ minutes), moderate ( $2-5$ minutes), and difficult (>5 minutes). An English translation of the polyp registration form is available in the Supplementary material.

\section{Outcomes}

The primary outcome of interest was the proportion of incompletely removed polyps. An incompletely removed polyp was defined as the presence of remnant polyp tissue in the biopsies taken from the resection margins after polypectomy (positive margin biopsies). Secondary outcomes included the differences between endoscopists in rate of incomplete polyp removal and risk factors associated with incomplete polypectomy.

The study was approved by the Norwegian Centre for Research Data and the need for further ethical approval was waived by the regional ethics committee of South-East Norway. Written, informed consent was obtained from all participants before the colonoscopy.

\section{Statistics}

Descriptive statistics are presented as mean with minimum and maximum values. For the assessment of risk factors predicting incomplete polyp resection, we first calculated the unadjusted odds ratio (OR) of incomplete resection in univariate logistic regression analyses using age, sex, histopathology of polyp, level of difficulty of polypectomy, polypectomy method (hot vs. cold snare, submucosal injection or not), size and location of polyp, and endoscopist experience (dichotomized to board-certified and trainee gastroenterologists) as explaining factors. There was no interaction between level of difficulty and size of polyp $(P>0.05)$. Logistic regression models were fitted to identify factors explaining incomplete resection. We estimated the 
probability of incomplete polyp resection for each endoscopist in the study, adjusting for case mix (polyp size, location, level of difficulty of polypectomy, age and sex of patient, histologic diagnosis of the polyp). We chose to only include those endoscopists who removed 10 or more polyps in the individual analyses. To take account of the fact that each individual could have more than one polyp, we used generalized estimating equations models, with compound-symmetry covariance structure. All analyses were conducted with Stata software version 14.2 (StataCorp, College Station, Texas, USA), and $P<0.05$ was considered statistically significant.

\section{Results}

A total of 246 patients with 339 polyps were included from four different hospitals. A total of 12 polyps were excluded due to cautery damage of the biopsies, which precluded histopathological examination. Accordingly, 327 polyps in 246 patients (mean age 67 years [range 42-83]; $52 \%$ male) were eligible for analysis. A total of 112 colonoscopies (52.4\%) were screening colonoscopies, 71 (28.9\%) were due to symptoms, and 63 (25.6\%) were classified as "other" indication for colonoscopy (e. g. polyp surveillance). The mean polyp size was $9.1 \mathrm{~mm}$ and $64.5 \%$ of the polyps were located proximally to the splenic flexure. A total of 197 polyps (60.2\%) had adenomatous histology ( $\triangleright$ Table 1). Of the 21 endoscopists participating in the study, 10 contributed more than 10 polyps.

\section{Incomplete resection of polyps 5-19 mm}

A total of 301 polyps were sized 5-19 mm. Of these, 44 (14.6\%) in 44 patients were incompletely resected (> Table 2 ). Two polyps had carcinomatous histology and were removed from the analyses. In univariate analyses, increasing polyp size was associated with incomplete resection. Polyps 5-9 mm were incompletely resected in $13.2 \%$ of the polypectomies, whereas $18.8 \%$ of polyps $10-19 \mathrm{~mm}$ were incompletely resected. The unadjusted OR for incomplete resection was 1.6 (95\% confidence interval $[\mathrm{Cl}]$ 1.0-2.5) for every 5-mm increase in polyp size. Sessile serrated adenomas/polyps (SSA/Ps) were incompletely resected in 24 of 65 polypectomies (36.9\%), and adenomas were incompletely resected in 11 of 184 polypectomies (6.0\%). The unadjusted OR was $9.2(95 \% \mathrm{Cl} 4.2-20.3)$ for incomplete resection of SSA/Ps and $3.5(95 \% \mathrm{Cl} 1.3-8.9)$ for incomplete resection of hyperplastic polyps compared with adenomas. The OR of incomplete resection when polyps were removed with EMR was $1.8(95 \% \mathrm{Cl} 0.8-3.9)$ in univariate analysis. Positive margin biopsies were present in $14.0 \%$ and $14.2 \%$ of polypectomies performed by experienced and unexperienced endoscopists, respectively $(P=0.55)$.

In the total sample of 327 resected polyps $\geq 5 \mathrm{~mm}, 54$ polyps (16.5\%) were incompletely resected. Polyps $\geq 20 \mathrm{~mm}$ were incompletely resected in 10 polypectomies (38.5\%).

\section{Factors explaining incomplete resection}

In the multivariate regression model, polyp histology and polyp location in the proximal colon were independent risk factors. The adjusted OR for incomplete removal of polyps $5-19 \mathrm{~mm}$
- Table 1 Polyp and procedure characteristics $(n=327)$.

\begin{tabular}{|c|c|}
\hline Characteristics & Polyps, n (\%) \\
\hline \multicolumn{2}{|l|}{ Size } \\
\hline - $5-9 \mathrm{~mm}$ & $220(67.3)$ \\
\hline - $10-19 \mathrm{~mm}$ & $81(24.8)$ \\
\hline - $\geq 20 \mathrm{~mm}$ & $26(7.9)$ \\
\hline \multicolumn{2}{|l|}{ Morphology } \\
\hline - Flat & $162(49.5)$ \\
\hline - Elevated & $133(40.7)$ \\
\hline - Uncertain & $32(9.8)$ \\
\hline \multicolumn{2}{|l|}{ Localisation ${ }^{1}$} \\
\hline - Proximal colon & $211(64.5)$ \\
\hline - Distal colon & $116(35.5)$ \\
\hline \multicolumn{2}{|l|}{ Histology } \\
\hline - Adenomas & $197(60.2)$ \\
\hline - High grade dysplasia & $7(3.6)$ \\
\hline - Low grade dysplasia & $190(96.4)$ \\
\hline \multicolumn{2}{|l|}{ Serrated polyps } \\
\hline - SSA/P & $75(22.9)$ \\
\hline - Hyperplastic polyps & $53(16.2)$ \\
\hline - Carcinomas & $2(0.6)$ \\
\hline \multicolumn{2}{|l|}{ Resection } \\
\hline - En bloc & $246(75.2)$ \\
\hline - Piecemeal & $81(24.8)$ \\
\hline \multicolumn{2}{|l|}{ Method for polypectomy } \\
\hline - Cold snare & $67(20.5)$ \\
\hline - Hot snare & $260(79.5)$ \\
\hline \multicolumn{2}{|l|}{ EMR } \\
\hline - No & $89(27.2)$ \\
\hline - Yes & $238(72.8)$ \\
\hline \multicolumn{2}{|c|}{ Polypectomy level of difficulty² } \\
\hline - Easy & $176(53.8)$ \\
\hline - Moderate & $108(33.0)$ \\
\hline - Difficult & $43(13.2)$ \\
\hline \multicolumn{2}{|c|}{$\begin{array}{l}\text { SSA/P, sessile serrated adenoma/polyp; EMR, endoscopic mucosal resection. } \\
11 \text { Right flexure was included in ascending colon; left flexure was included in } \\
\text { transverse colon. } \\
{ }^{2} \text { Level of difficulty was defined by how time-consuming the polypectomy } \\
\text { was: easy < } 2 \text { minutes; moderate } 2-5 \text { minutes; difficult }>5 \text { minutes. }\end{array}$} \\
\hline
\end{tabular}


- Table 2 Multivariate logistic regression analyses for factors associated with incomplete polypectomy.

\begin{tabular}{|c|c|c|c|c|}
\hline & $\mathbf{n}$ & $\begin{array}{l}\text { Incomplete resection, } \mathbf{n}(\%) \\
{[95 \% \mathrm{Cl}]}\end{array}$ & $\begin{array}{l}\text { Multivariate analysis polyps } \\
5-19 \mathrm{~mm} \text {, OR ( } 95 \% \mathrm{Cl})\end{array}$ & $\begin{array}{l}\text { Multivariate analysis all } \\
\text { polyps, OR }(95 \% \mathrm{Cl})\end{array}$ \\
\hline Total number of polyps & 325 & $54(16.0)$ & & \\
\hline \multicolumn{5}{|l|}{ Size } \\
\hline - $5-9 \mathrm{~mm}$ & 219 & $29(13.2)[9.3-18.4]$ & 1.0 (Reference) & 1.0 (Reference) \\
\hline . $10-19 \mathrm{~mm}$ & 80 & $15(18.8)[11.6-28.9]$ & $0.8(0.3-1.9)$ & $0.8(0.4-1.8)$ \\
\hline - $\geq 20 \mathrm{~mm}$ & 26 & $10(38.5)[21.8-58.4]$ & & $2.0(0.5-7.4)$ \\
\hline \multicolumn{5}{|l|}{ Morphology } \\
\hline - Elevated & 131 & $15(11.5)[7.0-18.2]$ & 1.0 (Reference) & 1.0 (Reference) \\
\hline - Flat & 162 & $33(20.4)[14.8-27.3]$ & $0.7(0.3-1.7)$ & $0.7(0.3-1.6)$ \\
\hline - Uncertain & 32 & $6(18.8)[8.5-36.3]$ & $0.6(0.2-2.2)$ & $0.6(0.2-2.0)$ \\
\hline \multicolumn{5}{|l|}{ Location-segment $^{1}$} \\
\hline - Distal colon & 115 & $8(7.0)[3.5-13.4]$ & 1.0 (Reference) & 1.0 (Reference) \\
\hline - Proximal colon & 210 & $46(21.9)[16.8-28.0]$ & $2.8(1.0-7.7)$ & $2.5(1.0-6.2)$ \\
\hline \multicolumn{5}{|l|}{ Histology } \\
\hline - Adenomas & 197 & $15(7.6)[4.6-12.3]$ & 1.0 (Reference) & 1.0 (Reference) \\
\hline - Hyperplastic polyps & 53 & $10(18.9)[10.4-31.8]$ & $4.2(1.7-10.4)$ & $3.6(1.5-8.5)$ \\
\hline . SSA/P & 75 & $29(38.7)[28.3-50.2]$ & $10.9(3.9-30.1)$ & $8.5(3.4-21.5)$ \\
\hline \multicolumn{5}{|l|}{ Resection } \\
\hline - En bloc & 245 & $32(13.1)[9.4-17.9)$ & 1.0 (Reference) & 1.0 (Reference) \\
\hline - Piecemeal & 80 & $22(27.5)[18.8-38.4]$ & $0.8(0.3-1.9)$ & $1.0(0.4-2.3)$ \\
\hline \multicolumn{5}{|l|}{ Method for polypectomy } \\
\hline - Cold snare & 67 & $9(13.4)[7.1-24.0]$ & 1.0 (Reference) & 1.0 (Reference) \\
\hline - Hot snare & 258 & $45(17.4)[13.3-22.6]$ & $0.6(0.2-1.8)$ & $0.6(0.2-1.9)$ \\
\hline \multicolumn{5}{|l|}{ Use of EMR } \\
\hline - No & 89 & $9(10.1)[5.3-18.4]$ & 1.0 (Reference & 1.0 (Reference) \\
\hline - Yes & 236 & $45(19.1)[14.5-24.6]$ & $0.9(0.3-2.9)$ & $1.1(0.4-3.3)$ \\
\hline \multicolumn{5}{|c|}{ Polypectomy level of difficulty² } \\
\hline - Easy & 175 & $18(10.3)[6.6-15.8]$ & 1.0 (Reference) & 1.0 (Reference) \\
\hline - Moderately difficult & 107 & $22(20.6)[13.9-29.3]$ & $1.4(0.5-3.8)$ & $1.4(0.5-3.5)$ \\
\hline - Difficult & 43 & $14(32.6)[20.2-48.0]$ & $3.1(0.6-15.4)$ & $2.9(0.7-11.3)$ \\
\hline \multicolumn{5}{|l|}{ Endoscopists experience ${ }^{3}$} \\
\hline - Trainee & 169 & $27(16.0)[11.2-22.3]$ & 1.0 (Reference) & 1.0 (Reference) \\
\hline - Board-certified & 156 & $27(17.3)[12.1-24.1]$ & $1.0(0.5-2.1)$ & $0.9(0.5-1.7)$ \\
\hline \multicolumn{5}{|c|}{$\begin{array}{l}\text { OR, odds ratio; } \mathrm{Cl} \text {, confidence interval; } \mathrm{SSA} / \mathrm{P} \text {, sessile serrated adenoma/polyp; } \mathrm{EMR} \text {, endoscopic mucosal resection. } \\
{ }^{1} \text { Both flexures were included in the proximal colon. } \\
{ }^{2} \text { Level of difficulty was defined by the polypectomy procedure time: easy<2 minutes; moderate } 2-5 \text { minutes; difficult }>5 \text { minutes. } \\
{ }^{3} \text { Endoscopist experience dichotomized to board-certified and trainee gastroenterologist. }\end{array}$} \\
\hline
\end{tabular}


- Table 3 Results from multivariate logistic regression. Covariates in the multivariate model were: age and sex of patients; size, location, and histology of polyps; type of resection; and level of difficulty of polypectomy.

\begin{tabular}{|c|c|c|c|c|}
\hline Endoscopist & $\begin{array}{l}\text { No.of } \\
\text { removed } \\
\text { polyps }\end{array}$ & $\begin{array}{l}\text { Incomplete resection, } \\
\text { n (\%) }\end{array}$ & $\begin{array}{l}\text { Multivariate analysis polyps } \\
5-19 \mathrm{~mm}, \text { OR ( } 95 \% \mathrm{Cl})\end{array}$ & $\begin{array}{l}\text { Multivariate analysis all polyps, } \\
\text { OR }(95 \% \mathrm{Cl})\end{array}$ \\
\hline 1 & 39 & $4(10.3)$ & 1.0 (Reference) & 1.0 (Reference) \\
\hline 2 & 64 & $9(14.1)$ & $1.78(0.26-12.10)$ & $1.44(0.36-5.81)$ \\
\hline 3 & 35 & $5(14.3)$ & $1.57(0.20-12.25)$ & $1.55(0.31-7.81)$ \\
\hline 4 & 19 & $3(15.8)$ & $3.62(0.40-32.92)$ & $1.64(0.30-8.95)$ \\
\hline 5 & 17 & $3(17.7)$ & $2.75(0.36-21.20)$ & $1.86(0.29-12.02)$ \\
\hline 6 & 20 & $4(20.0)$ & $7.60(0.73-78.73)$ & $2.23(0.41-12.03)$ \\
\hline 7 & 30 & $7(23.3)$ & $2.85(0.48-17.08)$ & $2.72(0.64-11.59)$ \\
\hline 8 & 11 & $3(27.3)$ & $6.44(0.82-50.76)$ & $3.28(0.62-17.30)$ \\
\hline 9 & 44 & $13(29.5)$ & $2.40(0.28-20.59)$ & $3.68(0.95-14.19)$ \\
\hline 10 & $12^{*}$ & $0(0.0)$ & & \\
\hline
\end{tabular}

was $10.9(95 \% \mathrm{Cl} 3.9-30.1)$ for SSA/P and $4.2(95 \% \mathrm{Cl} 1.7-10.4)$ for hyperplastic polyps compared with adenomas ( $\bullet$ Table 2 ). Polyps located in the proximal colon had over 2 times adjusted OR compared with polyps located in the distal colon (OR 2.8, $95 \% \mathrm{Cl} 1.0-7.7)$. Size, morphology, en bloc vs. piecemeal resection, the use of EMR, endoscopist experience, and level of difficulty were not significantly associated with incomplete resection in the multivariate model.

\section{Difference between endoscopists}

- Table 3 shows the incomplete resection rate for each endoscopist who removed 10 polyps or more. Adjusting for case-mix, the incomplete resection rate varied from $6.7 \%$ to $34.6 \%$ ( Fig. 2). In the multivariate analysis, none of the endoscopists performed statistically significantly worse than the best performing endoscopist.

\section{Complications}

There was one serious complication during polypectomy $(0.3 \%)$. In this patient, the polypectomy resulted in colon perforation and the patient underwent surgery. The patient had a 30-mm SSA/P located in the cecum, which was removed by piecemeal resection using hot snare polypectomy technique. A further three patients had intraprocedural bleeding and five had bleeding after biopsies from the resection margins. All bleedings were successfully treated during the same colonoscopy session.

The 12 polyps that were excluded from the analysis due to heat damage in the biopsy specimens were included in a sensitivity analysis in which they were defined as incompletely resected, without any change to the results.

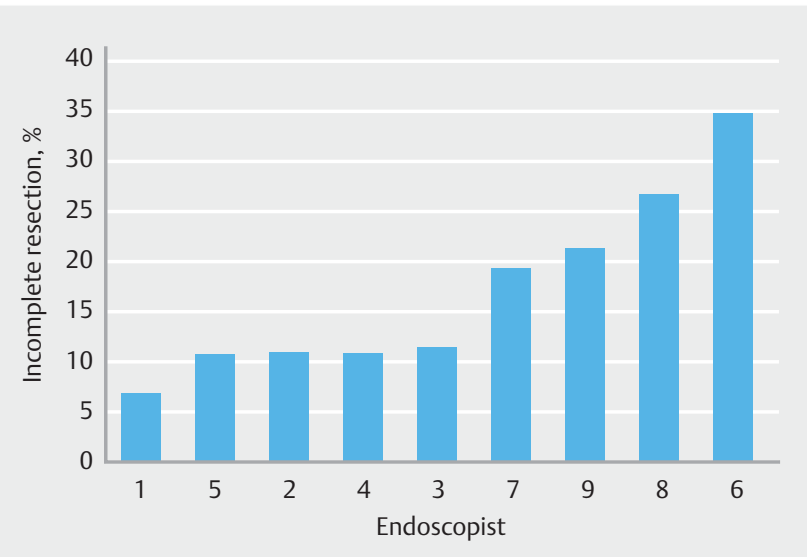

Fig. 2 Proportions of incomplete polypectomy. The columns show the predicted incomplete polyp resection risk for each endoscopist who removed at least 10 polyps during the study period, adjusted for case mix (age and sex of patients; polyp size, location, and histology; endoscopic mucosal resection; hot or cold snare resection; en bloc or piecemeal resection; level of difficulty of polypectomy [defined by polypectomy time: easy < 2 minutes; moderate 2-5 minutes; difficult gt; 5 minutes]).

\section{Discussion}

In our study, as many as 1 in 6 polyps were incompletely resected. Independent factors for incomplete resection were serrated histology and proximal location. There was a wide variation between individual endoscopists, and being a board-certified endoscopist was not associated with better performance compared with trainees. Notably, polyp size was correlated with incomplete resection only in univariate analysis. 
The incomplete resection rate in our study is higher than previously reported. In the CARE study, the incomplete resection rate was $10.1 \%$ [12] for polyps measuring between 5 and $20 \mathrm{~mm}$. In the present study, the incomplete resection rate of polyps with similar size was $14.6 \%$. Two previous studies reported recurrence rates of $16 \%$ and $31.7 \%$ in polyps $\geq 20 \mathrm{~mm}$, whereas we found residual polyp tissue among $38.5 \%$ of polyps of a similar size $[6,14]$. Of note, the design of our study was similar to the CARE study, whereas the recurrence was detected at a second colonoscopy in the latter two studies $[6,12,14]$.

The results found in the present study, mirrored by the three studies mentioned above, stand in contrast to those provided by an Italian report [15]. Among 163 polyps removed by EMR, the rate of incomplete resection of SSA/Ps $\geq 10 \mathrm{~mm}$ was only $1.2 \%$ [15]. The reason for this discrepancy is unclear; however, in the Italian study, all lesions were removed by cold snare EMR, whereas almost all our SSA/Ps were removed by hot snare EMR. Other investigators have shown no difference between hot and cold snare polypectomy in polyps $<1 \mathrm{~cm}$ in size $[16,17]$, but more research is needed to confirm whether cold snare EMR may be a better option for removal of larger SSA/Ps.

Or results clearly showed that the most important factor for incomplete polypectomy was serrated histology, SSA/Ps being incompletely removed in almost $40 \%$ of the polypectomies. SSA/Ps are believed to be associated with up to $30 \%-35 \%$ of CRCs [18], underlining the importance of complete removal $[19,20]$. Improved polypectomy technique is clearly needed, and the results from the Italian EMR study [15] indicate that cold snare polypectomy may be a good choice for these polyps and should be tested in randomized trials. Furthermore, modern technology such as computer-assisted technology, snare tip soft coagulation, and chromoendoscopy [21-23] may also be helpful in identifying and completely removing SSA/Ps, as well as in determining their extent in the colon mucosa.

Following all polypectomies, inspection with both whitelight and narrow-band imaging was performed; however, 16\% of polyps were still incompletely resected. One reason for this may be that the use of electrocautery makes the evaluation of the resection margins difficult.

In accordance with previous reports [24,25], we found that proximal polyp location was an independent factor for incomplete resection. This finding was independent of both size and histology of the polyps, implying that polypectomy is more technically challenging in the proximal colon. Proximal location is also associated with more complications after polypectomy [25]. A likely interpretation is that the endoscopists need to be more alert and thorough when removing polyps in the proximal colon. Importantly, previous studies have shown that post-colonoscopy cancer is more frequent in the proximal colon [26, 27]. Post-colonoscopy cancers may be caused by either new lesions, overlooked lesions, or incompletely removed lesions [7, $28,29]$. The latter two are procedural factors. In several studies, these modifiable factors have been shown to explain the majority of post-colonoscopy cancers [8, 29].

Neither polyp size nor level of procedural difficulty were independent risk factors for incomplete polypectomy in the multivariate model. This result was somewhat surprising and should be interpreted with caution due to the limited sample size. However, there may also be another explanation: endoscopists may be more aware of the risk of incomplete resection in large and difficult-to-remove polyps, and may therefore be more vigilant during these procedures.

We also found that the differences between the endoscopists were substantial, with a range in incomplete resection rate from approximately $10 \%$ to $30 \%$ in the unadjusted analysis. However, the two endoscopists with statistically significantly poorer performance compared with the best performing endoscopist in the multivariate analysis had very wide $\mathrm{Cls}$, and the study was not powered to analyze these differences. Accordingly, these results should be interpreted with caution.

We found that the risk of incomplete polyp resection was not related to the experience of the endoscopist. Incomplete resection rates in our study were $17.3 \%$ and $16.0 \%$ among boardcertified gastroenterologists and trainees, respectively. One may argue that this result is not surprising as the experienced endoscopist may have supervised all polypectomies performed by the trainee. However, after initial training, polypectomies in the Norwegian setting are usually performed without direct supervision; the endoscopist is only called if specific problems are encountered. It cannot be ruled out that the trainees in our study were extremely skilled, but our finding may also have important implications: increasing experience may not necessarily transfer into improved clinical practice, and all endoscopists, regardless of experience, should adhere to quality assurance programs. Finally, our results may imply that not all experienced endoscopists are good teachers for trainees in endoscopy, and education of endoscopists is probably important regardless of the level of experience. It should also be noted that our findings might not be generalizable to other settings where trainee gastroenterologists receive more hands-on supervision of polypectomies than in our setting.

Few studies have been conducted in the field of education of endoscopists in polypectomy skills. Van Doorn tested a lecturebased polypectomy training program, where endoscopists recorded five polypectomies, attended three classes with education in polypectomy by experienced endoscopists, and thereafter recorded five additional polypectomies, which were subject to evaluation by the Direct Observation Polypectomy Skills (DOPyS) method [30]. DOPyS is a set of measures that an experienced endoscopist may use to assess the quality of polypectomy (e.g. optimizing the polyp position, choosing the correct snare size, using appropriate polypectomy technique). There was no statistically significant difference between the polypectomy performance before and after the lectures. The authors concluded that direct feedback and hands-on training in the endoscopy suite by experienced endoscopists are the best ways to improve polypectomy skills, but this was not tested in their study. Another study by Duloy et al. showed that using report cards, where endoscopists recorded their baseline DOPyS score before watching polypectomy instruction videos, significantly increased the DOPyS score from the baseline polypectomy [31]. The increase was only statistically significant for polypectomies of diminutive polyps. The DOPyS method might 
be a good way to improve polypectomy skills, but it has yet to be fully validated [32].

Quality indicators for polypectomy are scarce. The European Society of Gastrointestinal Endoscopy guidelines include only one: using snare for polyps larger than $3 \mathrm{~mm}$ [33]. Our study calls for more rigorous quality assurance of polypectomy competence. The risk of post-polypectomy cancers within a defined time period would obviously be the gold standard but these events are rare and cumbersome to measure. An alternative would be to perform audits using DOPyS, or regularly obtain margin biopsies after polypectomy of a defined number of procedures per endoscopist. Those with poor technique or high incomplete resection rates could then undergo additional training. As shown in our study, case-mix influences incomplete resection rates and must be taken into account when performance of individual endoscopists is compared. Importantly, we show that obtaining margin biopsies is a safe procedure. The risk of bleeding was small (1.5\%) and all bleedings were immediately and successfully treated.

The strengths of this study are the inclusion of all types of polyps of all sizes above $5 \mathrm{~mm}$, and multiple sites and endoscopists. Furthermore, all polyps in this study were removed at community hospitals, and by endoscopists with varying experience, increasing the external validity of our results. There are also important limitations that should be highlighted. We obtained margin biopsies to assess complete polyp removal, as has been done in previous studies $[12,16]$. This methodology has not been validated, but our results probably represent a lower boundary for incomplete resection as the presence of additional undetected residual polyp tissue would only increase the proportion of nonresected polyps. Furthermore, the clinical significance of residual polyps is not clear. Not all polyps will progress to cancers, resected or not. Many polyps, both small adenomas and large serrated polyps may not increase in size, and some may even regress [34,35].

Importantly, selection bias cannot be ruled out. Our trial was conducted in a busy real-life setting including many endoscopists, and consecutive inclusion of patients was not possible to achieve. Accordingly, there may have been selection of polyps that were easier to remove or when a sufficient time slot was available. Our results may therefore represent the lower level of incomplete resection. Nevertheless, the incomplete resection rate was substantial and higher than previously reported [12].

The resection margins were examined with both white-light and narrow-band imaging after polypectomy, but $16 \%$ of polyps were still incompletely resected. This may be due to difficulty in assessing the resection margins either because of a lack of endoscopist skill in identifying residual polyp tissue or because of the effects of electrocautery.

In conclusion, we show that in an unselected outpatient colonoscopy cohort in Norway, incomplete polyp resection was frequent, with serrated histology and proximal location identified as independent risk factors. The performance of board-certified gastroenterologists was not superior to that of trainee gastroenterologists. Quality assurance and improved education of endoscopists at all levels of experience are important measures to minimize the rate of incomplete polypectomy.

\section{Competing interests}

The authors declare that they have no conflicts of interest.

References

[1] Holme O, Loberg M, Kalager M et al. Effect of flexible sigmoidoscopy screening on colorectal cancer incidence and mortality: a randomized clinical trial. JAMA 2014; 312: 606-615

[2] Atkin WS, Edwards R, Kralj-Hans I et al. Once-only flexible sigmoidoscopy screening in prevention of colorectal cancer: a multicentre randomised controlled trial. Lancet 2010; 375: 1624-1633

[3] Holme O, Schoen RE, Senore C et al. Effectiveness of flexible sigmoidoscopy screening in men and women and different age groups: pooled analysis of randomised trials. BMJ 2017; 356: i6673

[4] Lin JS, Piper MA, Perdue LA et al. Screening for colorectal cancer: updated evidence report and systematic review for the US Preventive Services Task Force. JAMA 2016; 315: 2576-2594

[5] Farrar WD, Sawhney MS, Nelson DB et al. Colorectal cancers found after a complete colonoscopy. Clin Gastroenterol Hepatol 2006; 4: 1259-1264

[6] Moss A, Williams S], Hourigan LF et al. Long-term adenoma recurrence following wide-field endoscopic mucosal resection (WF-EMR) for advanced colonic mucosal neoplasia is infrequent: results and risk factors in 1000 cases from the Australian Colonic EMR (ACE) study. Gut 2015; 64: 57-65

[7] Robertson DJ, Lieberman DA, Winawer SJ et al. Colorectal cancers soon after colonoscopy: a pooled multicohort analysis. Gut 2014; 63: 949-956

[8] le Clercq CM, Bouwens MW, Rondagh E] et al. Postcolonoscopy colorectal cancers are preventable: a population-based study. Gut 2014; 63: 957-963

[9] Carter D, Beer-Gabel M, Zbar A et al. A survey of colonoscopic polypectomy practice amongst Israeli gastroenterologists. Ann Gastroenterol 2013; 26: 135-140

[10] Singh N, Harrison M, Rex DK. A survey of colonoscopic polypectomy practices among clinical gastroenterologists. Gastrointest Endosc 2004; 60: 414-418

[11] Pedersen IB, Loberg M, Hoff G et al. Polypectomy techniques among gastroenterologists in Norway - a nationwide survey. Endosc Int Open 2018; 6: E812-E820

[12] Pohl H, Srivastava A, Bensen SP et al. Incomplete polyp resection during colonoscopy - results of the complete adenoma resection (CARE) study. Gastroenterology 2013; 144: 74-80.e71

[13] Zhang Q, Gao P, Han B et al. Polypectomy for complete endoscopic resection of small colorectal polyps. Gastrointest Endosc 2018; 87: 733-740

[14] Knabe M, Pohl J, Gerges C et al. Standardized long-term follow-up after endoscopic resection of large, nonpedunculated colorectal lesions: a prospective two-center study. Am J Gastroenterol 2014; 109: 183-189

[15] Tutticci NJ, Hewett DG. Cold EMR of large sessile serrated polyps at colonoscopy (with video). Gastrointest Endosc 2018; 87: 837-842

[16] Aslan F, Camci M, Alper E et al. Cold snare polypectomy versus hot snare polypectomy in endoscopic treatment of small polyps. Turk J Gastroenterol 2014; 25: 279-283 
[17] Kawamura T, Takeuchi Y, Asai S et al. A comparison of the resection rate for cold and hot snare polypectomy for 4-9 mm colorectal polyps: a multicentre randomised controlled trial (CRESCENT study). Gut 2018; 67: 1950-1957

[18] Singh R, Zorron Cheng Tao Pu L, Koay D et al. Sessile serrated adenoma/polyps: Where are we at in 2016? World J Gastroenterol 2016; 22: 7754-7759

[19] Bettington M, Walker N, Clouston A et al. The serrated pathway to colorectal carcinoma: current concepts and challenges. Histopathology 2013; 62: 367-386

[20] Langner C. Serrated and non-serrated precursor lesions of colorectal cancer. Dig Dis 2015; 33: 28-37

[21] Djinbachian R, Dube AJ, von Renteln D. Optical diagnosis of colorectal polyps: recent developments. Curr Treat Options Gastroenterol 2019; 17: $99-114$

[22] Picot J, Rose M, Cooper K et al. Virtual chromoendoscopy for the realtime assessment of colorectal polyps in vivo: a systematic review and economic evaluation. Health Technol Assess 2017; 21: 1-308

[23] Kandel P, Werlang ME, Ahn IR et al. Prophylactic snare tip soft coagulation and its impact on adenoma recurrence after colonic endoscopic mucosal resection. Dig Dis Sci 2019; 64: 3300-3306

[24] Lee SP, Sung IK, Kim JH et al. Risk factors for incomplete polyp resection during colonoscopic polypectomy. Gut Liver 2015; 9: 66-72

[25] Heldwein W, Dollhopf M, Rosch T et al. The Munich Polypectomy Study (MUPS): prospective analysis of complications and risk factors in 4000 colonic snare polypectomies. Endoscopy 2005; 37: 11161122

[26] Brenner H, Chang-Claude J, Rickert A et al. Risk of colorectal cancer after detection and removal of adenomas at colonoscopy: population-based case-control study. J Clin Oncol 2012; 30: 2969-2976
[27] Brenner $\mathrm{H}$, Hoffmeister $\mathrm{M}$, Arndt $\mathrm{V}$ et al. Protection from right- and left-sided colorectal neoplasms after colonoscopy: population-based study. J Natl Cancer Inst 2010; 102: 89-95

[28] Adler J, Robertson DJ. Interval colorectal cancer after colonoscopy: exploring explanations and solutions. Am J Gastroenterol 2015; 110: 1657-1664

[29] Pohl H, Robertson DJ. Colorectal cancers detected after colonoscopy frequently result from missed lesions. Clin Gastroenterol Hepatol 2010; 8: 858-864

[30] van Doorn SC, Bastiaansen BA, Thomas-Gibson S et al. Polypectomy skills of gastroenterology fellows: can we improve them? Endosc Int Open 2016; 4: E182-E189

[31] Duloy AM, Kaltenbach TR, Wood M et al. Colon polypectomy report card improves polypectomy competency: results of a prospective quality improvement study (with video). Gastrointest Endosc 2019; 89: $1212-1221$

[32] Gupta S, Bassett P, Man R et al. Validation of a novel method for assessing competency in polypectomy. Gastrointest Endosc 2012; 75: 568-575

[33] Kaminski MF, Thomas-Gibson S, Bugajski M et al. Performance measures for lower gastrointestinal endoscopy: a European Society of Gastrointestinal Endoscopy (ESGE) quality improvement initiative. United European Gastroenterol J 2017; 5: 309-334

[34] Holme O, Bretthauer M, Eide TJ et al. Long-term risk of colorectal cancer in individuals with serrated polyps. Gut 2015; 64: 929-936

[35] Vleugels JLA, Hazewinkel Y, Fockens P et al. Natural history of diminutive and small colorectal polyps: a systematic literature review. Gastrointest Endosc 2017; 85: 1169-1176.e1161 